\title{
Themes within lecturers' views on the teaching of linear algebra
}

Ragnhild Johanne Rensaa (a), Ninni Marie Hogstad (b) and John Monaghan (b)

(a) Department of Electrical Engineering UiT The Arctic University of Norway, Narvik, Norway;

(b) Department of Mathematical Sciences, University of Agder, Kristiansand, Norway

\begin{abstract}
This paper reports on themes that arose in an investigation of university lecturers' views on the teaching of linear algebra. This focus on themes was the initial part of a study concentrating on four areas: what is important to teach in a first course in linear algebra?; are there teaching methods which are particularly suited for such a course?; are there tools that should/should not be used; and do the answers to these questions vary according to the degree (Engineering or Mathematics) the students follow? Questionnaire data was coded using thematic analysis which generated 11 themes related to the four questions above. The Results section presents the themes. The Discussion section considers: the themes as a whole; splits - dualities - in teaching linear algebra; students' challenges with abstraction; aspects of doing mathematics; and pedagogical issues.
\end{abstract}

Keywords: linear algebra, teaching, thematic analysis, lecturers' views, students' needs

\section{Introduction}

The teaching of linear algebra and, in particular, difficulties in teaching an introductory course, is a long-standing concern of researchers. As stated by Hillel, 'The teaching of linear algebra at a university level is almost universally regarded as a frustrating experience for instructors and students alike' [1, p. 191]. This paper brings the teaching situation to the fore, by presenting the opinions of a panel of experts on the teaching of linear algebra. The thematic analysis applied to these opinions advances research in the area by presenting a nuanced list of issues concerning the teaching of linear algebra. 
Linear algebra is a compulsory course both for Mathematics and Engineering students, and a discipline where students often meet the demands of a formal approach to mathematics for the first time. This leaves many students feeling that they 'have the feeling of having landed on a new planet and are not able to find their way in this new world' [2, p. 86]. Subjective reports state teaching in this landscape as difficult, like Carlson [3] in his broadlycited paper "Teaching linear algebra: Must the fog always roll in?". Carlson points to several reasons for students' difficulties including: lack of mathematical maturity; algorithms which depend on context; students' lack of experience in dealing with concepts; and the introduction of a number of concepts that lack connection to students' prior mathematical knowledge. Instructors find that teaching in this pedagogical landscape a challenging task. With reference to Brousseau's didactical obstacles, [4] referring both to narrow or insufficient instruction and obstacles due to the abstraction level of mathematics, Harel [5] outlines a teaching experiment addressing obstacles for linear algebra, commenting on inadequate attention to conceptual understanding, the mixture of concepts, ideas and symbolism which are disconnected from students' previous experiences, and also the role of geometry. Similar comments, though not in the language of Brousseau, were given by our expert panel as they responded to questions on the teaching of linear algebra.

Discussions of specific content in the teaching of linear algebra is, of course, important. The European Society of Engineering Education (SEFI), considered further below, offers a detailed list of topics that could be included in a linear algebra course, ranging from educational levels 0 to 3 [6]. Along with these lists, SEFI suggests competencies needed when dealing with the topics, together with knowledge and skills that students should acquire at each level. SEFI's remit is engineering mathematics but the topics listed are, to a large degree, relevant for Mathematics students too, particularly with respect to introductory courses. The focus of our research, however, was not to compete with SEFI and our questionnaire asked the experts to avoid lists of topics and to focus on the nature of the teaching of linear algebra.

Dorier and Sierpinska [7] provides an overview of research in linear algebra education at the turn of the millennium. It ranges from content studies to investigations of students' difficulties in linear algebra and ends with teaching experiments and challenges. A recent book, [8], about research and practice in the teaching and learning of linear algebra revisits the same research topics but also focuses on the use of technology - digital tools - which are continuously advancing. Tucker [9], claims that the use of technology is one of the reasons 
why linear algebra attracts more and more students from disciplines other than mathematics, like students studying for an engineering degree. Our research interests complements the work of [7], [8] and [9] by focusing on issues of content, teaching, applications, and tool-use with regard to students on different education pathways. We present a thematic analysis of lecturers' views in order to grasp the larger educational picture of 'the what' and 'the how' of teaching linear algebra and focus on teaching situations of a general nature, illuminated through derived themes. This is done by implementing a three round Delphi study in which 14 university professors (called 'experts' in this paper), experienced in teaching linear algebra, offered their views on four issues. The Delphi method requires that experts answer questionnaires anonymously in several rounds, typically three. In our three round Delphi study the first round contained open questions for experts to answer and an analysis of these responses provides the foundation for the present paper. Our experts have a variety of backgrounds, described below, which, we hoped, would provide us with informed opinions to the following questions.

- What should be on a first year linear algebra undergraduate course for Engineering/Mathematics and to both Engineering and Mathematics students?

- How could such courses be taught?

- What tools (if any) are essential to these two groups of students?

We first present a literature review of linear algebra with regard to teachers' views on what should be taught and how it might be taught. We then outline the methodology including a description of the Delphi method for the overall project. We then concentrate on the methodology in Round 1, the focus of this paper, and how we managed the data sets. The results present themes and codes that emerged from data analysis. This is followed by a discussion of issues arising and a brief conclusion.

\section{Literature review}

Our literature review focuses on the three bulleted questions (content, teaching and tools) and on applications of linear algebra (the latter arose, as shall be seen, in experts' responses). The literature reviewed adds to a larger picture about what and how to teach linear algebra to Engineering students versus Mathematics students, and perceived differences between these students. 
When asking what is important to teach in linear algebra, an immediate answer would be to provide lists of contents according to which level the course is designed for. Such lists, however, has been provided by the SEFI's Mathematics Working Group [6]. These lists are found on the web so we do not elaborate on them here. Although the SEFI list focuses on engineering education, most of the linear algebra content is generic and of value for Mathematic students. Linear algebra involves a process of abstraction, going from concrete objects, tools and procedures in visible vector spaces $\left(R^{2}\right.$ and $\left.R^{3}\right)$, to generalizations, theory and unifications at a more abstract level. The subject often contains a large number of definitions and the use of formalism, which may not link to students' prior mathematical experiences. From a didactical point of view, most examination problems in traditional linear algebra courses may be solved by algorithms and procedures, the meaning of which need not to be understood, e.g. Gaussian row eliminations. As a result, students may not see any gain in learning formal theory. They are inexperienced with proofs and have difficulties understanding both why proofs are needed and the various proof techniques [10]. Such difficulties with formal aspects of linear algebra are not only connected to the formalism itself but also to the difficulty of understanding the specific use of formalism in theory and concepts. In a diagnostic study by Dorier, Robert, Robinet and Rogalski, this difficulty is termed the 'obstacle of formalism' [2]. Further problems may arise if students interpret formal concepts in intuitive contexts. Linear algebra represents a move between different representations; functions is a good example of this. In linear algebra, functions may be seen as objects in themselves, vectors, which may be added, multiplied by scalars and combined. Such new conceptual structures and generalisations require a different level of thinking and a substantial range of mental processes $[11,12]$. This is connected to the variety of 'languages' used in the subject; Hillel [1] distinguishes three, geometric, algebraic and abstract languages. Transfer between these languages requires cognitive flexibility, which may present difficulties to students [7]. Using geometry as a motivation for, and an interpretation of, linear algebra concepts may provide more intuitive contexts and produce a solid basis for students' understanding but may, at the same time, restrict students' ability to abstract [5, 11]. Hillel [1] also warns about geometric representations that may mislead students if taken too literally.

Harel [11] suggests three principles for teaching linear algebra: the Concreteness Principle; the Necessity Principle; and the Generalisation Principle. We consider these at some length as they resonate with some of the results from our study. The Concreteness 
Principle concerns building students' understanding of linear algebra concepts in a context that appears concrete to them. This involves use of concrete models of structures, in linear algebra this is often done by drawing on geometric illustrations. This delivery aspect is further emphasised by Hannah, Stewart and Thomas [13], which points to visualisations as metaphors for the more general ideas. This paper supports lecturers' use of visual imaginary, both by using physical objects and pictures, as a means of encouraging conceptual thinking. However, two- and three-dimensional geometric visualisations of linear algebra concepts may be viewed figuratively by students as spatial objects rather than representations of more abstract images. While teachers may have no problem seeing how a geometric situation is isomorphic to an algebraic one, many students do not share this insight [11]. The Necessity Principle builds on students' identification of a mathematical need for knowledge in order to solve a problem. Teaching, Harel argues, must then be organised in such a way that essential knowledge becomes necessary if the students are to succeed in a linear algebra course. The Generalisability Principle concerns didactic decisions regarding the choice of teaching material which allows and encourages the generalization of concepts. Harel [11] raises concerns that this principle is offered for the sake of the Concreteness Principle; models used in instructions may be so specific that they turn out to have little in common with the general concept they are supposed to serve as illustration of. An example is pictures of linear dependent vectors in $R^{2}$, which are not easily generalizable to general vector spaces.

Some researchers draw attention to the use of tools, concrete or visual, as means for increasing students' cognitive flexibility. Dogan [14], for example, reports on the effects of dynamic visual representations of the linear independent concept to students' mental images. She found notable differences between students who were and were not subjected to such representations using a web-module. Dogan's students seemed to utilize their acquired geometry-based knowledge in sense-making of more abstract linear algebraic ideas; introducing students to dynamic geometric tasks, Dogan argues, may have important benefits in structuring students' initial knowledge. A similar argument holds for the use of tools in the teaching environment of linear algebra.

Harel [15] emphasises that linear algebra is important not just because it introduces students to mathematical abstraction but also because of its wide range of applications in areas such as engineering and statistics. This is because of its power to model real situations, thus being a valuable tool in problem solving, modelling and applications (see [8]). Thinking 
in practical ways, however, may create incorrect understandings if it is not properly extended to theoretical aspects of linear algebra [16]. Research has warned that developing applicable courses in linear algebra may result in an inadequate attention to conceptual understanding [5]; as stated by Harel:

Our students demand that the material in a course be less abstract and more concrete, or "down-to-earth". I believe that, often, what students are really asking is for us to give them more computational procedures they can imitate. We, the teachers, don't like the idea of doing that, but we do like the idea of having a lot of applications in our courses. So we give them their recipes and call it applications [5, p.71].

In most of the studies cited above, students are referred to in general - the authors do not distinguish between Mathematics and Engineering students. However, as pointed out by Steen [18], for students who study Mathematics as part of a professional program, contextbased mathematics is appealing. Learning can be enhanced by giving mathematical concepts 'engineering meaning' [19]. This is discussed in [20], where Engineering students describe the learning of linear algebra in conceptual terms, but the students emphasize the importance of applications and problem solving as part of their learning. Also, Engineering students frequently perceive and process the information they get visually [21], given in different forms by digital visual tools, paper-based representations and gestures. This arguably underlines the importance of applications, geometric representations and different teaching styles in linear algebra classes of Engineering students.

\section{Methodology}

We describe the Delphi method (3.1), our Round 1 data and coding (3.2), the thematic analysis (3.3) and validity and reliability issues (3.4).

\subsection{The Delphi method}

In a Delphi method, the focus is on eliciting views, on a matter of importance for a community, from experts from that community, (see [22] for further details). Delphi methods employ an initial questionnaire (first round) to solicit opinions on the matter of importance and follows this up by feeding first round information back to the same responders for further comment (second round); this feedback-response may be repeated. A schematic illustration of the Delphi method is given in Figure 1. 


\section{[Insert Figure 1 near here]}

The figure illustrates the three rounds with feedback, starting with responses from experts to open questions in a questionnaire in Round 1. Based on analysis of the responses, a set of statements constitute the questionnaire in Round 2, analysed and refined before distributed in a Round 3 questionnaire. The analysis of the final round provides a twice refined overview of the opinions of the experts.

Delphi studies are deliberately not administered face-to-face, to allow responders time for a considered response and to preserve anonymity. Such studies draw attention to expert opinion but it is up to the reader to value these opinions or not. Our Delphi study was conducted by researchers following a socio-cultural approach and in an interpretivist paradigm.

Our three-round Delphi study focused on the teaching of linear algebra. We describe the first round, a questionnaire on the teaching of linear algebra, in some detail below. Round 2 presented themes from Round 1 and our panel rated the importance of these themes. Round 3 is similar to Round 2 with themes given low importance removed. The minimum number for a Delphi panel is considered to be 10 [22]; our panel had 14 members. Since we work in Norway, we wanted to include Norwegians in the panel, but not just Norwegians and not too wide a spread of nations; the panel was thus composed of Mathematics university professors from four northern European countries. All experts were fluent in English and the questionnaires and the responses were all in English. The panel was composed to ensure that every cell in Table 1 was filled with at least one member.

[Insert Table 1 near here]

The numbers in the 3 by 3 sub-table denote the number of experts assigned to each cell. The columns represent the kinds of students the experts have taught. The rows represent the experts' personal research expertise: 'Mathematics' means research in mathematics; 'Education' means research into university mathematics education; 'Education \& Mathematics' means both education and mathematics - these are people who started their careers as straight mathematicians but developed significant expertise in educational matters. The Round 1 questionnaire, sent from and received by a server that kept the identities of the responders secret, had five questions:

Q1 What is important to teach in a first course in linear algebra? 
Q2 Are there methods of teaching that are particularly suited or not suited to linear algebra?

Q3 Are there specific tools (techniques, software, etc) that should or should not be used in the study of linear algebra?

Q4 Do any of your answers from (1) to (3) vary according to whether the students are studying Engineering or Mathematics? If so, how?

The questions were designed as a means to address the questions in the three bullets in the introduction section but the wording is not identical. For example, Q1 asks about 'what is important to teach' whereas the first bullet question asks 'what should be on'. The Q1 wording was designed to avoid answers just providing a list of topics. The part of the first bullet question concerning different types of students was deliberately moved to the end (Q4) to allow for unprompted comments on different students in Q1, Q2 and Q3. A fifth question asked experts for any other comments, but this was only used for comments such as "Not really". All 14 experts responded in Round 1.

\subsection{Data and coding}

The data obtained was text. The responses were quite long; the mean number of words for responses to Q1 was 1134. The original data was transformed a little in that some parts of some Q1 responses were copied to later questions. For example, when a response in Q1 mentioned using Maple, this was copied to Q3. The data was coded using thematic analysis. Braun and Clarke [23] suggest the steps: (1) data familiarization; (2) generating initial codes; (3) searching for themes; (4) reviewing themes; and (5) naming themes. Our work in generating codes and themes closely followed these steps but we note that there came a point where themes emerged before codes were completely saturated (we suspect this is a general phenomenon). All three authors were equally involved in coding and each author's codes were scrutinized by the other two. We kept an on-going list of codes and themes and engaged with constant comparison over the coding/theming process. This process continued until no further codes or themes emerged.

\subsection{Thematic analysis in more detail}

As a start, all authors familiarized themselves with the data by reading it several times. This was followed by initial coding both separately and together. Codes developed based on interpretations of the text. To exemplify our analysis, we pick the following quote: 
Exercises in linear algebra typically are divided into two categories, either where you are to calculate something (e.g. rank of a matrix), or relatively simple, more abstract, exercises where you have to prove general properties ... In the second category of exercises, students are expected to reason on a somewhat more general level ... The inevitable consequence is that it is, in general, too challenging to give many abstract exercises, in particular on the final exam. Thus, exercises from the first category dominates, explaining to a certain degree why students find the course relatively manageable (respondent 7)

The quote was initially coded as 'Assessment'. In the step 'searching for themes,' the code 'Assessment' of the above quote was included in a theme we called Pedagogical issues and conditions. This theme, however, at this point in the thematic analysis had other codes connected to it, the importance of time and of textbooks in a linear algebra course.

The next step in the thematic analysis process was reviewing the themes. By rereading the data again with themes at hand, patterns within each theme were revealed. For instance, quotes that had been coded 'Connecting Concepts' were found to have pedagogical importance since connecting concepts is an aspect of student understanding. Thus, 'Connecting Concepts' was placed within the Pedagogical issues and conditions theme. This process of re-assigning codes to themes represented the first stage of the reviewing themes step of our thematic analysis. The second stage was a similar search for patterns but related to the entire set of data. At this point in our analysis, a code we ended up calling 'LA-split' (described in detail below) emerged. Reviewing our data with regard to this new code revealed a number of ways in which our experts saw splits in the teaching of linear algebra, including an 'LA-split' in the quote cited above; the quoted expert emphasises the difficulty between exercises where you are to calculate something concrete like rank and exercises where you have to prove more general properties. This, we considered, represented a split between procedural and conceptual tasks. Further, this specific split was viewed as an aspect of mathematics itself and the LA-split code was included in the theme Linear algebra as a discipline. Such working, back and forth between themes and codes, was a constant feature of the reviewing themes step. The final step in the thematic analysis was naming themes. This step, in our work, could be called 'refining theme names' as it involved modifying some theme names to faithfully describe the themes to which new codes had been added. 


\subsection{Validity and reliability issues}

In developing our themes, their objective existence and the extent to which they represent consensus views may be of concern. The themes do not have an objective existence, they are the joint creations of three researchers; another three researchers could have produced different themes. We do, however, feel that the way we applied thematic analysis to the data was rigorous - the themes are an honest interpretation. The themes are not supposed to reflect a consensus views of our expert panel. Apart from agreements between experts about the necessity to introduce matrices, vectors and Gauss elimination in a linear algebra course, there was no clear consensus between them; their responses emphasised various perspectives. Obtaining measures of consensus on statements related to the themes, however, is the prime purpose of Round 2 and 3 of the Delphi method and is not reported on in this paper.

With regard to reliability, we had initially intended to follow a standard inter-coder reliability (ICR) iteration exercise of a second coder re-coding a first coder's codes until greater than $85 \%$ agreement was reached. We found, however, that our individual codings on samples of responses, compared in regular three-person meetings, were converging to $100 \%$ agreement, so we did not follow the standard ICR exercise.

\section{Results}

This section presents the data-generated themes for each of our questions. For Question 1, 2 and 3 themes, codes and brief descriptions are presented in tabular form. Some codes, for example, 'Mathematical objects', from Question 1 (Q1), also appeared in Q2, Q3 and Q4, but we do not repeat these codes in later tables. After each table, further clarification of the meaning of the themes is exemplified by quotes from our respondents (experts), identified by an alpha-numeric, i.e. R7 for respondent 7. As explained in 4.4 below, themes for Q4 are not presented in tabular form.

\subsection{Four themes for Q1: What is important to teach?}

In coding responses to the question 'What is important to teach?' four themes crystalized. Although we asked the experts to avoid giving lists of linear algebra concepts, some of the explanations referred to specific linear algebra objects to illustrate their meaning, and these cases were coded 'Mathematical objects' in a theme called Linear algebra as a discipline. Themes, with codes and clarifications, are presented in Table 2, followed by selected quotes. [Insert Table 2 near here] 
The theme Aspects of doing linear algebra concerns that which students should be able to do. An example of a response coded within this theme is:

Exercises in linear algebra typically are divided into two categories, either where you are to calculate something (e.g. rank of a matrix), or relatively simple, more abstract, exercises where you have to prove general properties (e.g. if $\mathrm{AB}=\mathrm{BA}$, then an eigenspace for $\mathrm{A}$ is invariant under B). (R7)

The quote was coded 'Technique', "to calculate", and 'Generalisations and abstractions'. It also relates to an LA-split, as it concerns procedural and conceptual abilities.

The theme Problem solving, modelling and applications has three codes with the same three names. Coding was, in general, unproblematic - if "problem solving" was written, then 'Problem solving' was the code. However, there were times, such as the R4 quote below, when a term appeared to have nuanced meanings,

Systems of equations are linked to more abstract concepts such as linear span, linear independence, subspaces, and bases. These notions are difficult for many students, but they are necessary to get a good grasp of most applications ... Most interesting applications are to other kinds of vector spaces, such as function spaces, matrix spaces etc. All students should get a view outside $R^{\wedge} n$ and $C^{\wedge} n$. (R4)

The first part was coded 'Applications' after the codes 'Mathematical objects' and 'Connecting concepts", where the reference "they are necessary" connected the codes. The second part was coded 'Applications' together with 'Mathematical objects' and 'Generalisations and abstractions'.

The theme Pedagogical issues and conditions concerns matters considered to be of pedagogical importance. The theme has six codes connected to it, one of which is "Textbooks". A response with this code is:

Looking at the textbooks in linear algebra, I see no particular disagreement what academic content such a course should have. The textbooks for a first course in linear algebra are almost identical, except for one thing - applications. (R10) 


\subsection{Two themes for Q2: Are there methods of teaching that are particularly suited or not suited to linear algebra?}

When analysing answers to the question about teaching methods, two themes were identified. These were about teaching differences with regards to linear algebra content and ways of working. Since what is important to teach is closely connected to methods of teaching, most of the codes developed in analyses of Q1 were also relevant in coding of Q2. These are not repeated, thus the presentation of themes, codes and clarifications in Table 3 only includes codes that were particular to the question about methods of teaching.

[Insert Table 3 near here]

An example of a response within theme Teaching differences regarding linear algebra content is the following:

It is important to give a very stringent teaching so that the students are able to argue by proofs in a stringent way. (R8)

This was coded as 'Traditional teaching' method since it states that proofs in linear algebra demands a 'stringent' way of teaching; we interpreted 'stringent' as meaning 'rigorous', which may be done by lecturing.

A response about Teaching differences informed by aims and ways of working points to the use of computers:

Much of the calculations done with matrixes are quite boring leading to no deeper insight. The use of computers will free time that can be used to focus on understanding and principles (R6) The way of working was coded as ICT both for teachers and students; by use of ICT, time is released for understanding. Additional codes, generated in Q1, for this quote were 'Students' understanding' and 'Time'.

\subsection{Two themes for Q3: Are there specific tools (techniques, software, etc) that should or should not be used in the study of linear algebra??}

Two themes were developed for the question about tools used in linear algebra: about specific tools to use; and for the purpose of using digital technology. Themes, codes and clarifications are given in Table 4.

[Insert Table 4 near here] 
The theme concerning specific tools to use is straightforward and includes pedagogic devices such as clickers as well as mathematical tools. An example of a statement about the purpose of using digital technology is:

When students become proficient in the use of, say, Matlab, they can be given "realistic" problems in linear algebra to address (they do not have to be confined to systems of 3 equations in 3 unknowns). This presents opportunities for group working in problem solving.

This quote concerns the use of ICT to handle tasks which involve large matrices and was coded 'Types of tasks or applications' and 'Using technology to handle large matrices'. The response also emphasises how the use of a mathematical tool may facilitate 'Group work' in a 'Problem solving' environment and interrelates to themes Pedagogical issues and conditions and Problem solving, modelling and applications.

\subsection{Three themes for Q4: Do your answers vary according to the students'subject?}

This forth question asked if teaching varies according students' degree in Engineering or Mathematics. Analysis of responses identified three themes: content differences; teaching differences; and distinctive characteristics for each group of students. Q4 raises issues already raised in Q1, Q2 and Q3 but with a particular focus on types of students, and existing codes could be drawn upon; we thus do not provide a separate table for this question. The aforementioned code 'LA-split' dominated the coding of this question.

The first theme for Q4 is Linear algebra content differences between Engineering students and Mathematics students. It includes responses suggesting that Engineering students should concentrate on learning a variety of linear algebra techniques and gaining knowledge about different types of applications of the subject, whilst Mathematics students should concentrate on abstract structures and formal mathematics.

The second theme in Q4 is Teaching differences between Engineering students and Mathematics students. This theme arose from responses suggesting that Engineering students need to be exposed to a variety of teaching methods in which problem solving activities feature whilst Mathematics students should have greater exposure to 'traditional' teaching formats which may be more suited for teaching proofs. An illustration of such argumentation is given by the following: 
If teaching to engineering students I would focus more on the technique, and the fact that they can compute correctly, as mathematics is more like a tool for solving engineering problems. If teaching to mathematics students I would focus more on the concepts and the relations between the concepts, the ability to abstract and generalize. I would also have more focus on theorem proofs, as being able to prove theorems is an important mathematical know-how.

Codes for this quote were 'Techniques' for Engineering students and 'Generalisations and abstractions' related to 'Mathematical objects' but also 'Mathematical cultural artefacts' for Mathematics students. The latter points to the expert's emphasis on proofs and proving.

The final theme for Q4 was Differences between types of students, including responses suggesting that being a student in an engineering programme implies a focus on wanting to know 'how' to find solutions while Mathematics students are interested in 'why'.

I think that mathematics students should focus more on proofs than engineering students. For engineering students focus should be put on applications. The meaning of theorems should be understood and applied but not proved. (R6)

This response also draws attention to a 'Mathematical cultural artefacts', proof, being a primary interest to Mathematics students with additional codes of 'Applications' and 'Understanding' of linear algebra results for Engineering students.

\section{Discussion}

In this section we reflect on: our thematic analysis; the code LA-split; and how the results of our study relate to the extant literature.

The themes, of course, reflect the questions in the questionnaire but, the majority of responses to Q1 included explanations which also addressed Q2 to Q4, so there is a sense in which teaching methods, tool use and differences between students were present in our expert panel's thoughts when they were asked 'What is important to teach?'. The themes certainly do not support a stereotype of a mathematics lecturer simply lecturing without regard to the audience: The Pedagogical issues and conditions theme arose from Q1 responses before the question on teaching methods was posed, so pedagogy was an issue from the start. Also, 11 of the 14 responses mentioned types or attributes of students in their Q1 responses, so the audience does matter. 
We began the thematic analysis half expecting to get independent themes, but this did not happen - many of the themes are interrelated. Two examples are: (i) the Q2 theme Teaching differences regarding linear algebra content has overlap with the Q4 theme Linear algebra content differences between Engineering students and Mathematics students; (ii) the 'use of computers' example presented above for the Q2 theme teaching differences informed by aims and ways of working, relates to the Q3 theme The purpose of using digital technology. This interrelatedness of some themes could be a criticism of our thematic analysis, but we hold that it reflects the complex interconnections in the minds of our expert panel as they consider what is important to teach in a linear algebra course.

A code we found particularly interesting was the code LA-split which, in the process of coding, arose in a number of themes. It seems important and it is not, to our knowledge, directly addressed in the literature. The code is associated with the Q1 theme Mathematics as a discipline, but splits occurred in the responses in a variety of ways. Some examples/quotes are: 'not just the techniques for calculating the eigenvalues and eigenvectors of a given matric but also some conceptual understanding of what these represent' was coded 'LA-split (concepts \& techniques)'; 'For Mathematics students, general vector spaces are an ideal introduction, for Engineering students it may be better to concentrate on spaces they will meet in typical applications' was coded 'LA-split (student and content)'; 'There should be two courses in linear algebra. A first course for all that focuses on matrix algebra, and a second ... that focuses on vector spaces and linear transformations' was coded 'LA-split (algebra \& vector spaces)'. A number of our experts also split the content into variations of mathematical cultural artefacts on one hand - including proofs, abstract structures and formal definitions and operations, like algorithms and techniques, on the other. The existence of this phenomena suggests the need for further research on splits in the teaching of linear algebra. This research could survey opinion but could also look into the taught content of linear algebra courses.

We now consider how the results of our study relate to the extant literature structured around three foci: students' challenges with abstraction; aspects of doing mathematics; and pedagogical issues. 
Our experts' emphasis on students' challenges with abstraction is a problem also stressed by researchers [7]. Experts stated their worries about students' lack of ability to move between different representations when working with the subject, particularly between concrete and abstract structures. This is in line with researchers' concerns, that it is a challenging process for students to shift between representations $[5,11,12]$. One of the responses, (R8), cited in the Results section above, suggested that a way to meet such challenges is by a 'stringent teaching method' when dealing with proofs. According to Harel [5], instruction may blend contexts, modes of description and notation, which may create a mixture of concepts, symbols and ideas among students studying linear algebra. This expert may be referring to something like Harel's blend but arguing that stringent teaching should be part of this blend. A number of experts also suggested geometric approaches where illustrations may serve as introductions to abstract forms. Research supports the use of such approaches since they may help produce a solid foundation for students' understanding of abstract linear algebra [11]. However, there are also warnings saying that students may confine their thinking to geometric vectors and not make progress to more general algebraic cases [1]. Some experts put forward the opinion that abstract content should be avoided when teaching linear algebra to Engineering students. They emphasised that Mathematics students must be introduced to abstract structures and proofs while Engineering students need to concentrate on structures they will meet in applications. Students' wishes for linear algebra material to be less abstract and more concrete is part of Harel's list of didactical obstacles [5], and refers to the important discussion of whether students should be taught mainly directly relevant mathematics or if they need wider perspectives. This was brought up by one of our experts, referring to 'Horizon knowledge' in mathematics, which is described by Ball and Bass to be a 'kind of mathematical "peripheral vision", a view of the larger mathematical landscape, that teaching requires' [24, p.1]. However, since 'Horizon knowledge' was only mentioned one time by one expert, the code for this kind of knowledge was discarded in the final review of themes. Still, the topic is important and merits further research.

Closely connected to linear algebra-content is Aspects of doing linear algebra, and LA-splits also arose in this theme. Many experts emphasised the need for students to gain knowledge of abstract arguments and general vectors spaces. At the same time, however, calculations and specific techniques - often pointing at Gauss elimination as central - were highlighted as important. Dorier and Sierpinska [7] point to difficulties students may have 
when going from concrete operations to abstract arguments and experts in our study upheld this difficulty. The experts suggested solutions such as introducing concepts in a specific order to highlight connections between concepts, variation in teaching methods that may support students' learning such as project work, flipped classroom arrangements and the use of technology. Dogan [14] observed notable benefits to students' who were exposed to dynamic visual representations in linear algebra and Harel $[5,11]$ found geometry to have an important role in students' understanding. However, Dogan points to the importance of integrating dynamic tasks in both in-class and outside-class activities; the importance of tailoring activities outside the linear algebra classroom is, as mentioned earlier, emphasised by Carlson [3]; 'I have come to believe that what I ask my students to do after class is as important as what I say and do in class, and that what they actually do is even more important' [3, p.33]. The experts in the present investigation also emphasised that the types of tasks that students work on is important. In our thematic analysis, three such approaches emerged: problem solving, modelling and applications ${ }^{1}$. Of these three, applications was the one mentioned most often. Some experts just stated 'applications' whilst others mentioned specific applications like harmonic motion and systems of differential equations. In the extant literature, the usefulness of linear algebra is mentioned by a number of researchers, e.g. [8], and Engineering students themselves emphasize applications of linear algebra as an important issue in their learning of the subject [20].

The above discussion, particularly students' difficulties with abstraction and moving between representations in linear algebra brings us to our final focus, Pedagogical issues and conditions. One of the experts in the present study emphasised diversity in background knowledge to be a problem, particularly with respect to Engineering students; s/he argued that a linear algebra-course for such students needs to start at a lower level, thus creating challenges in finishing the expected content. This is supported in the extant literature in as much as Dogan [14] suggests that the high level of formalism and abstract structures in linear algebra may be a reason why some learners experience a lack of connection to previous mathematical knowledge. It represents an LA-split where the split is between content and students. Even if such a view is not agreed to by all, there was a predominant opinion among

\footnotetext{
${ }^{1}$ Our experts used these terms in their responses but, understandably, they did not define them. Precise definitions of terms are often important but this is not the case with these terms in this paper as we report on lecturers' use of the terms.
} 
experts that teaching and content in linear algebra for Mathematics students should not be the same as for Engineering students. Mathematics students are expected to understand abstractions, proofs and relations between concepts more deeply than Engineering students, who merely need to be introduced to them. Engineering students, on their side, are expected to be motivated by applications taught in a problem solving format. Such responses may be explained by Harel's [11] three principles of teaching of linear algebra. For Engineering students, applications may be the motivating part. This is about the concreteness and necessity principles of teaching, in which Engineering students seek to know how to compute and solve engineering related problems. Mathematics students, on the other hand, are expected to learn more about abstract and general structures. This is within the generalisation principle of teaching and, as one expert suggested, a traditional teaching format using chalk and board may be suitable in this process. Harel [11] further stresses that students' understanding of concepts should be built in a context that appears as concrete to them, and to Engineering students this ought to be context-based mathematics and applications [19, 20].

\section{Conclusion}

The focus of this paper has been on the thematic analysis of our experts' opinions on the teaching of linear algebra. Eleven themes have been presented and considered in relation to the practice of teaching and the educational literature on linear algebra. But we close with comments on a phenomenon that permeated data analysis in our study, repeated reference to splitting content, methods of teaching, tools and students, i.e. varieties of the code LA-split. We consider the LA-split code to be pertinent to research on linear algebra. This is because linear algebra is referred to in the literature as a single thing which, of course, it is as an area of mathematics. But in the perceptions of the lecturers in the present study, dualities in teaching linear algebra appear; we teach linear algebras.

\section{Acknowledgement}

We thank MatRIC (www.matric.no) and UiT The Arctic University of Norway for financial support for this work. Sincere thanks to the 14 experts who gave their time freely over three rounds of questionnaires. 


\section{References}

[1] Hillel J. Modes of descriptions and the problem of representations in linear algebra. In: Dorier JL, editor. On the teaching of linear algebra. Dordrecht: Kluwer Academic Publisher; 2000. p. 191-207.

[2] Dorier JL, Robert A, Robinet J, et al. The obstacle of formalism in linear algebra In: Dorier JL, editor. On the teaching of linear algebra. Dordrecht: Kluwer Academic Publisher; 2000. p. 85-94.

[3] Carlson D. Teaching linear algebra: Must the fog always roll in? Coll Math J. 1993;24(1):29-40.

[4] Brousseau G. Theory of didactical situations in mathematics. New York: Kluwer Academic Publishers; 2002.

[5] Harel G. The learning and teaching of linear algebra: Observations and generalizations. J Math Behav. 2017.46:69-95.

[6] Alpers B. A framework for mathematics curricula in engineering education. 2013; Available from: http://sefi.htw-aalen.de/.

[7] Dorier JL, Sierpinska A. Research into the teaching and learning of linear algebra. In: Holton E, editor. The teaching and learning of mathematics at university level. Dordrecht: Kluwer Academic Publishers; 2001. p. 255-273.

[8] Stewart S, Andrews-Larson C, Berman A, et al, editors. Challenges and Strategies in Teaching Linear Algebra. Hamburg: Springer International Publishing AG; 2018.

[9] Tucker A. The growing importance of linear algebra in undergraduate mathematics. Coll Math J. 1993;24(1):3-9.

[10] Rogalski M. Pourquoi un tel échec de l'enseignement de l'algèbre linéaire? In: Commission inter-IREM universtité: Enseigner autrement les mathématiques en DEUG Première Année; 1990; p. 279-291.

[11] Harel G. Three principles of learning and teaching mathematics, particular reference to linear algebra: Old and new observations, In: Dorier JL, editor. On the teaching of linear algebra. Dordrecht: Kluwer Academic Publisher; 2000. p. 177-189. 
[12] Hillel J, Sierpinska A. On one Persistent Mistake in Linear Algebra. In: Proceedings of the 18th International Conference on the Psychology of Mathematics Education Vol.III; 1994; Lisbon; 1994. p. 65-72.

[13] Hannah J, Stewart S, Thomas M. Emphasizing language and visualization in teaching linear algebra. Int J Math Educ Sci Technol. 2013;44(4):475-489.

[14] Dogan H. Mental schemes of: Linear algebra visual constructs. In: Stewart S, AndrewsLarson C, Berman A, et al, editors. Challenges and Strategies in Teaching Linear Algebra. Hamburg: Springer International Publishing AG; 2018. p. 219-239.

[15] Harel G. Learning and teaching linear algebra: Difficulties and an alternative approach to visualizing concepts and processes. Focus Learn Probl Math. 1989;11(2):139-148.

[16] Sierpinska A. On some aspects of students' thinking in linear algebra. In: Dorier JL, editor. On the teaching of linear algebra. Dordrecht: Kluwer Academic Publisher; 2000. p. 209-246.

[17] Dubinsky E. Some thoughts on a first course in linear algebra at the college level. In: Carlson D, Johnson CR, Lay DC, et al, editors. Resources for teaching linear algebra (MAA Notes). Addison Wesley Longman; 1997. p. 85-106.

[18] Steen LA. Revolution of stealth: Redefining university mathematics. In: Holton D, editor. The teaching and learning of Mathematics at university level. Dordrecht: Kluwer Academic Publishers; 2001. p. 303-312.

[19] Maull W, Berry J. A questionnaire to elicit the mathematical concept images of engineering students. Int J Math Educ Sci Technol. 2000;31(6):899-917.

[20] Rensaa, R. J. (2017). Approaches to learning of linear algebra among engineering students. Paper presented at the CERME10 10th Congress of European Research in Mathematics Education, Dublin, Ireland.

[21] Hogstad, N. M., Isabwe, G. M. N., \& Vos, P. (2016). Engineering students' use of visualizations to communicate about representations and applications in a technological environment. Paper presented at the International Network for Didactic Research in University Mathematics 2016 Montpellier.

[22] Osborne J, Collins S, Ratcliffe M, et al. What "ideas-about-science" should be taught in school science? A Delphi study of the expert community. J Res Sci Teach. 2003;40(7):692720. 
[23] Braun V, Clarke V. Using thematic analysis in psychology. Qual Res Psychol. 2006;3(2):77-101.

[24] Ball DL, Bass H. With an eye on the mathematical horizon: Know mathematics for teaching to learners' mathematical futures. In: Proceedings of the 43rd Jahrestagung der Gesellschaft für Didaktik der Mathematik; 2009; Oldenburg, Germany: 2009. https://eldorado.tu-dortmund.de/bitstream/2003/31305/1/003.pdf. 
Table 1:

\begin{tabular}{|l|l|l|l|}
\cline { 2 - 4 } \multicolumn{1}{c|}{} & \multicolumn{2}{l|}{ Has taught linear algebra to } \\
\cline { 2 - 5 } \multicolumn{1}{c|}{ Engineers } & \multicolumn{2}{l|}{ Mathematicians } & $\begin{array}{l}\text { Engineers \& } \\
\text { Mathematicians }\end{array}$ \\
\hline Main professional focus & \multicolumn{2}{l}{} \\
\hline Education & 1 & 2 & 1 \\
\hline Mathematics & 2 & 2 & 1 \\
\hline Education \& Mathematics & 2 & 1 & 2 \\
\hline
\end{tabular}

Table 1: Attributes of the expert panel 
Table 2:

\begin{tabular}{|c|c|c|}
\hline Theme & Codes related to theme & Clarification \\
\hline $\begin{array}{l}\text { Linear algebra as } \\
\text { a discipline }\end{array}$ & $\begin{array}{l}\text { Mathematical objects } \\
\text { Order of introduction } \\
\text { Mathematical cultural } \\
\text { artefacts } \\
\text { LA-split }\end{array}$ & $\begin{array}{l}\text { Matrices, vectors, basis, ... } \\
\text { Sequencing how objects and concepts } \\
\text { build on each other } \\
\text { Things specific to mathematics, like } \\
\text { symbols, formal definitions, proofs } \\
\text { Dualities in Linear algebra as a } \\
\text { discipline, such as 'algebraic- } \\
\text { geometric' and 'concepts-techniques'. }\end{array}$ \\
\hline $\begin{array}{l}\text { Aspects of doing } \\
\text { linear algebra }\end{array}$ & $\begin{array}{l}\text { Techniques } \\
\text { Students' skills } \\
\text { Representations } \\
\text { Generalisations and } \\
\text { abstractions } \\
\text { Interpretations }\end{array}$ & $\begin{array}{l}\text { Row reduction, Gauss elimination, etc. } \\
\text { Knowing when and how to operate } \\
\text { techniques } \\
\text { Matrix forms, tables, graphs, etc. } \\
\text { From } 2 \text { to } 3 \text { to } n \text { dimensions; from } \\
\text { visual to abstract vector spaces; } \\
\text { abstract arguments. } \\
\text { Ability to interpret results }\end{array}$ \\
\hline $\begin{array}{l}\text { Problem solving, } \\
\text { modelling and } \\
\text { applications }\end{array}$ & $\begin{array}{l}\text { Problem solving } \\
\text { Modelling } \\
\text { Applications }\end{array}$ & $\begin{array}{l}\text { Strategies for solving problem, also } \\
\text { creatively in new situations } \\
\text { Translating a situation into a } \\
\text { mathematical language } \\
\text { Application of linear algebra to other } \\
\text { fields }\end{array}$ \\
\hline
\end{tabular}




\begin{tabular}{|c|c|c|}
\hline $\begin{array}{l}\text { Pedagogical } \\
\text { issues and } \\
\text { conditions }\end{array}$ & $\begin{array}{l}\text { Connecting concepts } \\
\text { Students' understanding } \\
\text { Students should } \\
\text { Prior understanding } \\
\text { Time } \\
\text { Assessment } \\
\text { Textbooks }\end{array}$ & $\begin{array}{l}\text { For instance, "Connecting column } \\
\text { space to matrix multiplication" } \\
\text { What students need to understand } \\
\text { What students need to be able to do } \\
\text { What students need to start a course in } \\
\text { linear algebra } \\
\text { With reference to time constraints or } \\
\text { to time to understand concepts } \\
\text { Any reference to assessment } \\
\text { Any reference to textbooks }\end{array}$ \\
\hline
\end{tabular}

Table 2: Themes, related codes and explanations for Q1 
Table 3:

\begin{tabular}{|c|c|c|}
\hline Theme & Codes related to theme & Clarification \\
\hline $\begin{array}{l}\text { Teaching } \\
\text { differences } \\
\text { regarding linear } \\
\text { algebra content }\end{array}$ & $\begin{array}{l}\text { Traditional teaching } \\
\text { Flipped classroom }\end{array}$ & $\begin{array}{l}\text { Lecturing and task solving sessions } \\
\text { Students introduced to linear algebra } \\
\text { material before class, classroom time } \\
\text { used for exploring topics in depth in } \\
\text { interaction with each other facilitated } \\
\text { by the teacher } \\
\text { Reference to specific software and/or } \\
\text { programming languages or to tasks } \\
\text { (e.g. image manipulation/large } \\
\text { matrices) }\end{array}$ \\
\hline $\begin{array}{l}\text { Teaching } \\
\text { differences } \\
\text { informed by aims } \\
\text { and ways of } \\
\text { working }\end{array}$ & $\begin{array}{l}\text { Group work } \\
\text { Project work } \\
\text { Students' use of ICT }\end{array}$ & $\begin{array}{l}\text { Students working together in teams to } \\
\text { solve tasks } \\
\text { Students' work to solve more complex } \\
\text { tasks, preferably in teams } \\
\text { As above for teacher's use of ICT but } \\
\text { with reference to student use of ICT }\end{array}$ \\
\hline
\end{tabular}

Table 3: Themes, new codes and clarifications for Q2 
Table 4:

\begin{tabular}{|c|c|c|}
\hline Theme & Codes related to theme & Clarification \\
\hline $\begin{array}{l}\text { Specific tools to } \\
\text { use }\end{array}$ & $\begin{array}{l}\text { Specific mathematics } \\
\text { packages } \\
\text { Programming languages } \\
\text { Computer labs } \\
\text { Pedagogic devices }\end{array}$ & $\begin{array}{l}\text { Python (but Maple and MatLab were } \\
\text { also mentioned as programming } \\
\text { languages) } \\
\text { Going to a computer cluster to learn a } \\
\text { computer algebra system } \\
\text { For instance clickers }\end{array}$ \\
\hline $\begin{array}{l}\text { The purpose of } \\
\text { using digital } \\
\text { technology }\end{array}$ & $\begin{array}{l}\text { Hand calculations } \\
\text { Using technology to handle } \\
\text { large matrices and structures } \\
\text { Types of tasks or applications }\end{array}$ & $\begin{array}{l}\text { When hand calculations are important } \\
\text { 'Large' was mentioned a number of } \\
\text { times in connection to ICT, as an } \\
\text { adjective for matrices, structures, } \\
\text { projects. } \\
\text { Tasks or applications suitable (or not) } \\
\text { for digital technology }\end{array}$ \\
\hline
\end{tabular}

Table 4: Themes, new codes and clarifications for Q3 
Figure 1

Feeding results

back to responders
Feeding results

back to responders

\begin{tabular}{|l|l|l|l|}
\hline \multicolumn{1}{|c|}{ Round 1 } & \multicolumn{1}{|c|}{ Round 2 } & \multicolumn{1}{c|}{ Round 3 } \\
\hline $\begin{array}{l}\text { - Questionnaire to } \\
\text { solicit opinions } \\
\text { - Analysis of results }\end{array}$
\end{tabular}$\quad \begin{aligned} & \begin{array}{l}\text { - Questionnaire based } \\
\text { on feedback in Round 1 } \\
\text { - Analysis of results }\end{array} \\
& \text { - }\end{aligned} \mid \begin{aligned} & \text { - Questionnaire based } \\
& \text { on feedback in Round 2 } \\
& \text { - Analysis of results }\end{aligned}$

Figure 1: Schematic illustration for the Delphi method 